\title{
The impact of mindfulness on psychosomatic complaints among firefighters: The mediator role of vicarious traumatization
}

\author{
Piergiorgio Argentero. Department of Brain and Behavioral Sciences, Unit of Applied Psychology, University of \\ Pavia, Italy \\ Ilaria Setti. Department of Brain and Behavioral Sciences, Unit of Applied Psychology, University of Pavia, Italy \\ Beatrice Piccoli. Department of Philosophy, Pedagogy and Psychology, University of Verona, Italy \\ Massimo Bellotto. Department of Philosophy, Pedagogy and Psychology, University of Verona, Italy
}

\begin{abstract}
Firefighters are at risk to develop post-traumatic and psychosomatic symptoms. But in order to face negative health effects they have psychological resources at their disposal, such as mindfulness. This study aims to test the a model by which intrusion predicts general dysphoria in response to mindfulness. Self-report measures were administered to Italian firefighters. Structural equation modelling shown that mindfulness did not directly influence general dysphoria: mediation analyses revealed its meaningful indirect effect via intrusion. The results suggest that mindfulness can lead to reduced symptoms of general dysphoria through low levels of intrusive thoughts.
\end{abstract}

Keywords: mindfulness; vicarious traumatization; psychosomatic complaints; firefighters

\section{INTRODUCTION}

It has been found that mindfulness increases well-being and decreases occupational stress (Bränström, Duncan, and Moskowitz, 2011; Brown and Ryan 2003). Indeed, the central aim of the present research is to study firefighters' health in relation to mindfulness (Brown and Ryan, 2003). The interest of studying rescuers is due to the evidence that they may develop symptoms (such as post-traumatic stress reactions and depression; Argentero and Setti, 2011) as results of the exposure to catastrophic events. Despite the frequent exposure to critical events, the majority of firefighters do not develop negative effects, thanks to personal resources (Meyer, Zimering, Daly, Knight, and Kamholz, 2012; Setti and Argentero, 2014). Therefore, the present study tests how mindfulness may influence psychosomatic firefighters' well-being. In particular, it has been examined the mediating process underlying the relationship between mindfulness and general dysphoria, as an indicator of psychosomatic malaise.

Mindfulness, defined as the moment-to-moment awareness of the present experience (Kabat-Zinn, 2003), is an important resilience resource which may be important in preventing post-traumatic reactions among high risk populations (Smith et al., 2011). Mindful people can closely observe and describe current perceptions, thoughts, and feelings and act with full awareness of them. Mindfulness may allow firefighters to maintain a full concentration on the emergency situation, decreasing the likelihood of dissociation after the critical event (Ozer, Best, Lipsey, and Weiss, 2008). In addition to this, mindfulness may be important for firefighters in facing not only acute but also chronic stressors.

Firefighters are subject to vicarious traumatization (VT; Figley, 1999; Setti and Argentero, 2012) that can be defined as the stress caused by helping others who are suffering or who have been traumatized (Figley, 1999, p. 10). Those who work in caring roles can develop the same negative effects of the direct victims: VT symptoms are identical to those of PTSD (Figley, 1999): re-experiencing the traumatic event through intrusive thoughts; avoidance of people and places that may recall the event; psychological hyperarousal responses, such as alert reactions. The present research is specifically focused on intrusive symptoms because they have been found to be the most widespread manifestations of VT (Argentero and Setti, 2011; Bride, 2007).

Despite these possible negative effects, mindfulness, can protect firefighters while facing heavy situations (Paton, Violanti, and Smith, 2003; Tedeschi and Calhoun, 2004). So the following hypothesis is formulated:

Hypothesis 1: mindfulness is negatively related to intrusive thoughts.

Beyond VT, several psychosomatic complaints have been registered among firefighters, such as musculoskeletal and respiratory problems, depression and anxiety (North et al., 2002). These literature 
evidences emphasize the importance of examining firefighters' psychosomatic well-being and, in particular, general dysphoria, in terms of minor depression symptoms. Based on some previous research (Morren et al., 2007), it can be assumed that the repeated exposure to critical events increases the probability to develop post-traumatic reactions (i.e. intrusive symptoms) that in turn may produce negative psychosomatic effects (i.e. general dysphoria).

More in detail, it can be hypothesized that intrusive symptoms may mediate the association of mindfulness with general dysphoria. Based on these theoretical arguments and on the first hypothesis, the following is proposed:

Hypothesis 2: intrusion mediates the relationship between mindfulness and general dysphoria.

\section{METHOD}

\subsection{Participants and procedure}

Study participants were 255 Italian firefighters, with $61.2 \%$ working as professionals and $38.8 \%$ as volunteers. $98 \%$ of the participants were male; the mean age was 37 years $(S D=8.66)$ with an average of 10.12 years of service $(S D=9.1)$. All employees were asked to fill in a paper-and-pencil questionnaire and demographic information was obtained.

\subsection{Measures}

- Mindfulness. The Mindful Awareness Attention Scale (MAAS; Brown and Ryan, 2003) has been used. High scores on the MAAS are typical of individuals who are attentive to their inner feelings and to their behaviors. The 15 items (e.g., "I rush through activities without being really attentive to them") are rated on a 6-point scale from 1 (almost always) to 6 (almost never).

- Intrusion. The 17 items of the Secondary Traumatic Stress Scale (STSS; Bride, Robinson, Yegidis, and Figley, 2004), developed to evaluate VT symptoms, are grouped in three sub-scales: arousal (e.g. "I felf jumpy"), intrusion (e.g. "Reminders of my work with clients upset me") and avoidance (e.g. "I was less active than usual"). The items are rated on a 5-point Likert scale from 1 (never) to 5 (very often). In the present study, only the sub-scale of intrusive symptoms has been used.

- General dysphoria. The general dysphoria sub-scale of the General Health Questionnaire-12 (GHQ-12; Goldberg and Williams, 1988) has been administered. GHQ-12 is a brief measure, useful for the screening of minor psychiatric illness. Its 12 items are grouped in three sub-scales: social dysfunction, loss of confidence, and general dysphoria. The last one (e.g. "Have you recently felt constantly under strain?") has been used in the present research in order to evaluate symptoms of minor depression. Responses are based on a 4-point Likert scale from 0 (better than usual/more so than usual/not at all) to 3 (much less than usuallmuch more than usual).

\subsection{Data Analysis}

The Structural Equation Model derived from the mediated-effects hypothesis was tested using AMOS 18. Testing was done in two steps: (a) testing of the measurement model and (b) testing of the structural model. The first step related the observed variables to the underlying constructs by means of Confirmatory Factor Analysis (CFA). The hypothesized model was a three-factor model in which all items loaded on the corresponding latent variable: mindfulness, intrusion and general dysphoria. This model was compared with an alternative one-factor model in which all items loaded on the same factor, in order to verify common method variance (Podsakoff, MacKenzie, Lee, and Podsakoff, 2003).

The fit of the models was evaluated using various indices: 1- the Non-Normed Fit Index (NNFI); 2- the Comparative Fit Index (CFI); 3- Root Mean Square Error of Approximation (RMSEA); 4- Standardized Root Mean Square Residual (SRMR). For NNFI and CFI values between .90 and .95 are acceptable. RMSEA and SRMR values indicate a good fit when they are smaller than or equal to .08. Competing models were compared based on the chi-square difference test in addition to the fit indices.

Before testing the mediation hypothesis, we need to identify the most appropriate structural model (e.g., Piccoli, 2013). Because were made no predictions as to whether the relationships in the model refer to partial or full mediation, two competing models were tested: a fully mediated model (Model 1) and a partially mediated model (Model 2). The partially mediated model differed from Model 1 for the direct path from mindfulness to general dysphoria. For testing mediating variable effects, we performed bootstrapping (Hayes, 2009): we drew 5,000 bootstrapping samples to get 95 per cent confidence 
intervals $(\mathrm{Cl})$. In particular, total and specific indirect effects are significant if zero is not contained in the lower-upper $\mathrm{Cl}$.

\section{RESULTS}

\subsection{Descriptive Statistics}

The means, the standard deviations and the correlations for all scales (with Cronbach's alphas) are reported in Table 1. As expected, the correlation matrix showed that mindfulness was negatively correlated to intrusive thoughts and to general dysphoria. Furthermore, intrusion was positively associated to general dysphoria.

Table 1. Means, Standard Deviations, Reliabilities (Cronbach's alpha) and Correlations among the variables

\begin{tabular}{lcclll}
\hline \multicolumn{1}{c}{ Variable } & $\mathrm{M}$ & $\mathrm{SD}$ & 1 & 2 & 3 \\
\hline 1. Mindfulness & 4.59 & .77 & $(.83)$ & & \\
2. Intrusion & 1.85 & .60 & $-.34^{* *}$ & $(.74)$ & \\
3. General dysphoria & .62 & .59 & $-.37^{\star *}$ & $.41^{\star \star}$ & $(.77)$ \\
\hline
\end{tabular}

Note. $\mathrm{N}=255$. Cronbach's alphas are shown in parentheses along the diagonal $\left({ }^{* *} \mathrm{p}<.01\right)$.

\subsection{Measurement Model}

The hypothesised measurement model with three latent variables (mindfulness, intrusion, general dysphoria) fitted the data well. These the results: $\chi^{2}{ }^{2}(62)=98.92$; NNFI $=.91$; CFI $=.93$; RMSE $=.05$; $\mathrm{SRMR}=.05$. The loading of the variables on their corresponding factor was satisfactory (ranging from .50 to .80$)$. Fit indices of the competing one-factor model were not admissible: $\chi^{2}(67)=224.22$; NNFI $=.65$; $\mathrm{CFI}=.70 ; \mathrm{RMSEA}=.10 ; \mathrm{SRMR}=.11$

\subsection{Structural Model}

Following the recommendation of James, Mulaik, and Brett (2006), the full mediation model represents the best choice of a baseline model. Thus, the fit of this model (Model 1) was compared with that of an alternative partial mediation model (Model 2). The full mediation model included two paths, one from the antecedent variable (mindfulness) to mediator (intrusion) and the other from the mediator to the outcome variable (general dysphoria). Therefore, it implies that mindfulness has only an indirect effect on general dysphoria through intrusion. The full mediation model fitted the data well: $\chi^{2}{ }^{2}(63)=92.24 ; \mathrm{NNFI}=.92, \mathrm{CFI}=$ $.93, \mathrm{RMSEA}=.04, \mathrm{SRMR}=.05$. The partially-mediated model (Model 2) was examined adding a direct path connecting mindfulness to general dysphoria. Also Model 2 showed good fit as suggested by the various fit indices: $\chi^{2}{ }_{(62)}=98.92$; NNFI $=.91, \mathrm{CFI}=.92, \mathrm{RMSEA}=.04, \mathrm{SRMR}=.05$. The results were similar to Model 1 and the chi-square difference test (for comparing competing models) was not significant: $\Delta \chi^{2}(1)$ $=6.68, p>.05$. Furthermore, the direct path from mindfulness to general dysphoria $(\beta=-.15)$ was not statistically significant. Therefore, the more parsimonious full mediation model (Model 1 ) was retained and used to examine the mediation hypothesis. Model 1 is presented in Figure 1 with the estimates among the variables.

Figure 1. Model 1 (full mediation model) with standardized path coefficients (variance explained is shown in brackets)

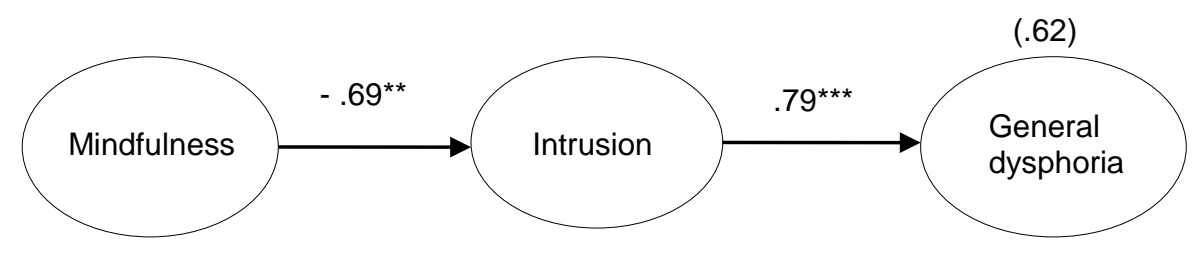


All the paths (shown in Figure 1), were statistically significant and according to the hypothesized direction. In particular, the path linking mindfulness and intrusion was negative and statistically significant $(\beta=-.69$, $p<.01$ ), supporting Hypothesis 1 . Furthermore, the path coefficient from intrusion to general dysphoria was positive and statistically significant $(\beta=.79, p<.001)$.

Hypotheses 2 predicted that intrusive thoughts mediated the relationship between mindfulness and dysphoria. In order to test the mediating role of intrusion, the significance of the indirect effect was tested with bootstrapping. The results support Hypothesis 2, considering the indirect effect: $-.41,95 \% \mathrm{Cl}=-.24$, .07 . Intrusion accounted for $62 \%$ of the relationship between mindfulness and general dysphoria.

\section{DISCUSSION}

The purpose of this study was to increase the knowledge about the impact of mindfulness on psychosomatic well-being among firefighters.

With regard to the first hypothesis, mindfulness was negatively related to intrusive thoughts: firefighters seem to be protected from the risk of developing malaise thanks to this resource. More in detail, individuals who pay attention to present moment have a low likelihood of developing post-traumatic effects (Brown and Ryan, 2003).

With respect to the second hypothesis, the results show that intrusion mediates the relationship between mindfulness and general dysphoria, whereas the direct relationship between them is not statistically significant.

Although this study provided some interesting results, it is limited in several respects. First, the data have been collected through a cross-sectional design, therefore future research should examine, with a longitudinal design, the prospective relationship between the variables. Secondly, some important dimensions that may protect firefighters' well-being have not been included. An organizational variable that might be considered is organizational climate, determinant of emergency workers' well-being (Burke and Paton, 2006). Another important variable is social support: high levels of perceived support could protect against post-traumatic symptoms (Meyer et al., 2012; Ozer et al., 2008). Among personal dimensions, there are optimistic disposition, hope and coping ability (Lazarus and Folkman, 1984). The third limitation regards the exclusive use of self-report data, so it was not possible to confirm findings through additional means of data (e.g., interviews). Finally, the sample is not fully representative of Italian firefighters: further investigations should be carried out.

From an applicative perspective, the results highlight the importance of preventative interventions aimed at reducing both acute stress after critic events and long-term malaise. More in detail, in order to face post-traumatic effects, critical incident stress debriefing (Mitchell and Everly, 1997) could be accomplished for the stress reduction in the aftermath of critic events (Burke and Paton, 2006). In addition, a constant psychological support is needed in order to help firefighters to increase their psychological resources, such as mindfulness, that in turn may reinforce their resilience (Brown and Ryan, 2003). With regard to this, mindfulness may be strengthened through specific training programs (Mindfulness-Based Stress Reduction) which support people in regulating their attention and focusing on in-the-moment experiences.

\section{REFERENCES}

Argentero, P. and Setti, I., "Engagement and Vicarious Traumatization in rescue workers", International Archives of Occupational and Environmental Health, Volume 84, Pages 67-75, 2011.

Bränström, R., Duncan, L. G., and Moskowitz, J. T., "The association between dispositional mindfulness, psychological well-being, and perceived health in a Swedish population-based sample", British Journal of Health Psychology, Volume 16, Pages 300-316, 2011.

Bride, B., "Prevalence of secondary traumatic stress among social workers", Social Work, Volume 52, Number 1, Pages 63-70, 2007.

Bride, B. E., Robinson, M. M., Yegidis, B., and Figley, C. R., "Development and Validation of the Secondary Traumatic Stress Scale", Research on Social Work Practice, Volume 14, Pages 27-35, 2004.

Brown, K. W. and Ryan, R. M., "The Benefits of Being Present: Mindfulness and Its Role in Psychological Well-Being", Journal of Personality and Social Psychology Copyright, Volume 84 , Number 4, Pages 822-848, 2003. 
Burke, K.J. and Paton, D., "Well-being in Protective Services Personnel: Organisational Influences", Australasian Journal of Disaster and Trauma Studies, Volume 2, Pages 1-13, 2006.

Figley, C. R., Compassion fatigue: toward a new understanding of the cost of caring, In B. H. Stamm (Ed.), Secondary traumatic stress (Pages 3-28). Towson, MD: Sidran Institute, 1999.

Goldberg D. P and Williams P., A user's guide to the General Health Questionnaire, NFER-Nelson, London, 1988.

Hayes, A. F., "Beyond Baron and Kenny: Statistical Mediation Analysis in the New Millennium", Communication Monographs, Volume 76, Pages 408-420, 2009.

James, L. R., Mulaik, S. A., and Brett, J. M., "A tale of two methods", Organizational Research Methods, Volume 9, Pages 233-244, 2006.

Kabat-Zinn, J., "Mindfulness-based interventions in context: past, present and future. Clinical Psychology", Science and Practice, Volume 10, Pages 144-156, 2003.

Lazarus, R. S. and Folkman, S., Stress, appraisal and coping, Springer, New York, 1984.

Meyer, E. C., Zimering, R., Daly, E., Knight, J., and Kamholz, B. W., "Predictors of posttraumatic stress disorder and other psychological symptoms in trauma-exposed firefighters", Psychological Services, Volume 9, Number 1, Pages 1-15, 2012.

Mitchell, J. and Everly, G.S., Critical incident stress debriefing - CISD: An operations manual for the prevention of traumatic stress among emergency service and disaster workers, Chevron, Elliot City, 1997.

Morren, M., Dirkzwager, A. J. E., Kessels, F. J. M., and Yzermans, C. J., "The influence of a disaster on the health of rescue workers: a longitudinal study", Canadian Medical Association, Volume 176, Number 9, Pages 1279-1283, 2007.

North, C. S., Tivis, L., McMillen, J. C., Pfefferbaum, B., Cox, J., Spitznagel, E. L., and Smith, E. M., "Coping, functioning, and adjustment of rescue workers after the Oklahoma City bombing", Journal of Traumatic Stress, Volume 15, Pages 171-175, 2002.

Ozer, E. J., Best, S. R., Lipsey, T. L., and Weiss, D. S., "Predictors of posttraumatic stress disorder and symptoms in adults: A meta-analysis", Psychological Trauma: Theory, Research, Practice, and Policy, Volume 1, Pages 3-36, 2008.

Paton, D., Violanti, J.M., and Smith, L.M. (eds.), Promoting capabilities to manage post-traumatic stress: Perspectives on resilience. Charles C. Thomas, Springfield, 2003.

Piccoli, B. "'Counterproductive Work Behaviours: Clarify the Role of Job Dissatisfaction and Organizational Injustice as Attitudinal Predictors", International Journal of Business Research, Pages 91-98, 2013.

Podsakoff, P.M., MacKenzie, S.B., Lee, J.Y. and Podsakoff, N.P., "Common method biases in behavioral research: a critical review of the literature and recommended remedies", Journal of Applied Psychology, Volume 88, Pages 879-903, 2003.

Setti, I., \& Argentero, P., "Vicarious trauma: a contribution to the Italian Adaptation of the Secondary Traumatic Stress Scale”, Bollettino di Psicologia Applicata, Volume 264, Pages 58-64, 2012.

Setti, I., \& Argentero, P., "The Role of Mindfulness in protecting Firefighters from Psychosomatic Malaise", Traumatology, An International Journal, Volume 20, Number 2, Pages 134-141, 2014.

Smith, B. W., Ortiz, J. A., Steffen, L. E., Tooley, E. M., Wiggins, K. T., Yeater, E. A., Bernard, M. L., "Mindfulness is associated with fewer PTSD symptoms, depressive symptoms, physical symptoms, and alcohol problems in urban firefighters", Journal of Consulting and Clinical Psychology, Volume 79, Number 5, Pages 613-617, 2011.

Tedeschi, R. G. and Calhoun, L. G., "Posttraumatic growth: Conceptual foundations and empirical evidence", Psychological Inquiry, Volume 15, Pages 1-18, 2004.

\section{AUTHOR PROFILE:}

Piergiorgio Argentero is Full Professor in Work and Organizational Psychology at the University of Pavia (Italy).

Ilaria Setti received her Ph.D. from the University of Pavia (Italy). Currently, she is post-doctoral fellow in Work and Organizational Psychology at the University of Pavia (Italy). E-mail: ilaria.setti@unipv.it

Beatrice Piccoli received her Ph.D. from the University of Verona (Italy) and Leuven (Belgium). Currently she is Research Assistant in Work and Organizational Psychology at the University of Verona.

Massimo Bellotto is Full Professor in Work and Organizational Psychology at the University of Verona (Italy). 